Revista da Rede Brasileira de História da Geografia e Geografia Histórica

$11 \mid 2019$

Mapas e mapeamentos: conhecer, apresentar e agir

\title{
¿Bromas cartográficas?
}

Los mapas alegóricos y satíricos como un modus scribendi para la crítica social

Cartographic jokes? Allegorical and satirical maps as a modus scribendi for social criticism

Blagues cartographiques? Les cartes allégoriques et satiriques comme modus scribendi pour la critique sociale

Brincadeiras cartográficas? Os mapas alegóricos e satíricos como um modus scribendi da crítica social

\section{Carla Lois}

\section{(2) OpenEdition}

\section{Journals}

Edición electrónica

URL: https://journals.openedition.org/terrabrasilis/3492

DOI: 10.4000/terrabrasilis.3492

ISSN: 2316-7793

Editor

Rede Brasileira de História da Geografia e Geografia Histórica

Referencia electrónica

Carla Lois, «¿Bromas cartográficas?», Terra Brasilis [En línea], 11 | 2019, Publicado el 31 agosto 2019, consultado el 05 diciembre 2022. URL: http://journals.openedition.org/terrabrasilis/3492 ; DOI: https:// doi.org/10.4000/terrabrasilis.3492

Este documento fue generado automáticamente el 5 diciembre 2022

All rights reserved 


\section{¿Bromas cartográficas?}

Los mapas alegóricos y satíricos como un modus scribendi para la crítica social

Cartographic jokes? Allegorical and satirical maps as a modus scribendi for social criticism

Blagues cartographiques? Les cartes allégoriques et satiriques comme modus scribendi pour la critique sociale

Brincadeiras cartográficas? Os mapas alegóricos e satíricos como um modus scribendi da crítica social

\section{Carla Lois}

Ver no es creer, sino interpretar. Las imágenes visuales tienen éxito o fracasan en la medida en las que podemos interpretarlas satisfactoriamente.

Nicholas Mirzoeff, Introducción a la cultura visual

\section{Introducción. La importancia de los mapas "fuera de la cartografía"}

1 A pesar de su apariencia ingenua o descontracturada, los mapas alegóricos y satíricos son poderosas herramientas para la crítica y la propaganda política (Barber y Board, 1993: 70). En muchos casos funcionan como una estrategia efectiva para hacer circular discursos críticos, por lo general ridiculizando personajes, lugares o eventos. Como son mapas que no pretenden ofrecer información geográfica, se permiten el uso de lenguajes gráficos y licencias poéticas para comunicar más eficazmente mensajes irónicos y críticos. Por tanto, mientras que la calidad de los llamados "mapas científicos" (ya sean topográficos o temáticos) es evaluada según la precisión de los datos medidos y representados o en una acertada elección de colores, se considera que 
los mapas alegóricos y satíricos están "bien hechos" cuando pueden ilustrar fácilmente ideas y conceptos complejos de forma comprensible o llamativa para los espectadores.

2 Para resultar eficaces, buscan establecer complicidad o connivencia con un lector informado capaz de acceder a sus declaraciones implícitas o connotadas dentro de una cultura (política y visual) específica, y están destinados principalmente a influir en las opiniones o creencias de los lectores.

3 En tanto dispositivos retóricos que transmiten significados no evidentes a través de figuraciones simbólicas (tipos humanos, animales o míticas), son fuertemente contextuales: fuera de contexto o sin tener información sobre el evento o la situación que se representa en el mapa, suelen resultar totalmente incomprensibles. Por eso no sorprende que, a veces, dado que los mapas alegóricos suelen ser piezas estéticamente bellas, que evocaban y evocan contenidos sofisticados (sobre mitología, historia, arte, religión), muchos de ellos fueron apenas utilizados como simples artefactos decorativos porque los usuarios ignoraban esos complejos niveles de significado.

Este tipo de mapas comparte con otras formas de sátira y alegoría el recurso retórico del pensamiento tópico entendido en un sentido amplio, como el arsenal de ideas o argumentos con los cuales, por un lado, el orador piensa y organiza su pensamiento y, por el otro, se prepara para persuadir a su auditorio (retórica stricto sensu) o convencer a un adversario. el orador debe seleccionar, hallar, en un repertorio prefijado de temas aquellos que son los más adecuados a su exposición (generalmente, lugares comunes, en fórmulas o clichés fijos y admitidos en esquemas formales o conceptuales). Sin embargo, a diferencia de la retórica satírica, los mapas de este tipo se caracterizar por un modus scribendi predominantemente gráfico y escueto en palabras. Eso significa que forman parte de una cultura visual específica, determinada histórica y socialmente, en donde el acontecimiento visual, que es la interacción entre el signo visual y el espectador puede darse debe existir un grupo social que domine cierta alfabetización visual que pueda leer ese modus scribendi.

5 Aunque estos mapas metafóricos, alegóricos y satíricos pueden parecer "chistes visuales" (Holmes, 1991: 173), abordan con sutil perspicacia una amplia gama de temas, entre ellos religiosos, políticos, militares, comerciales, morales y sociales. Dependiendo del mensaje y de la estética, los mapas alegóricos funcionaron simultáneamente como ilustraciones, como instrumentos pedagógicos, como guías religiosas y como propaganda política.

6 Este artículo propone examinar algunos casos emblemáticos de mapas satíricos y alegóricos con tres objetivos: en primer lugar, rastrear la arqueología de este tipo de mapas; en segundo lugar, definir los mapas satíricos y alegóricos como géneros cartográficos con sus propias especificidades; y, en tercer lugar, reflexionar sobre la función sociales de estos dispositivos como recursos expresivos.

\section{Una breve historia cultural de los mapas alegóricos y satíricos}

7 Para pensar la dimensión histórica de la pragmática de los mapas alegóricos y satíricos resulta útil recurrir a una interpretación y adaptación libre del método y la concepción de la arqueología del saber concebida por el filósofo francés Michel Foucault, es decir, la premisa de que los sistemas de pensamiento y conocimiento ("epistemes" o 
"formaciones discursivas") están regidos por reglas, más allá de las gramaticales y lógicas, que operan en la conciencia de los sujetos individuales y defines un sistema de posibilidades conceptuales que determinan los límites de un lugar y de un momento histórico dado. No obstante, a los efectos de este trabajo, esta noción foucaultiana debe ser complementada por la dimensión gráfica del saber, de la comunicación y de la conciencia individual y colectiva que opera en los modos de construir significados. En este sentido, los mapas "no cartográficos" pueden ser pensados como una forma particular de formaciones discursivas cuya historia nos aproxima a diferentes modos de expresar posibilidades conceptuales.

Figura 1. Mapamundi manuscrito de Opicinus de Canistris (1296-1300)

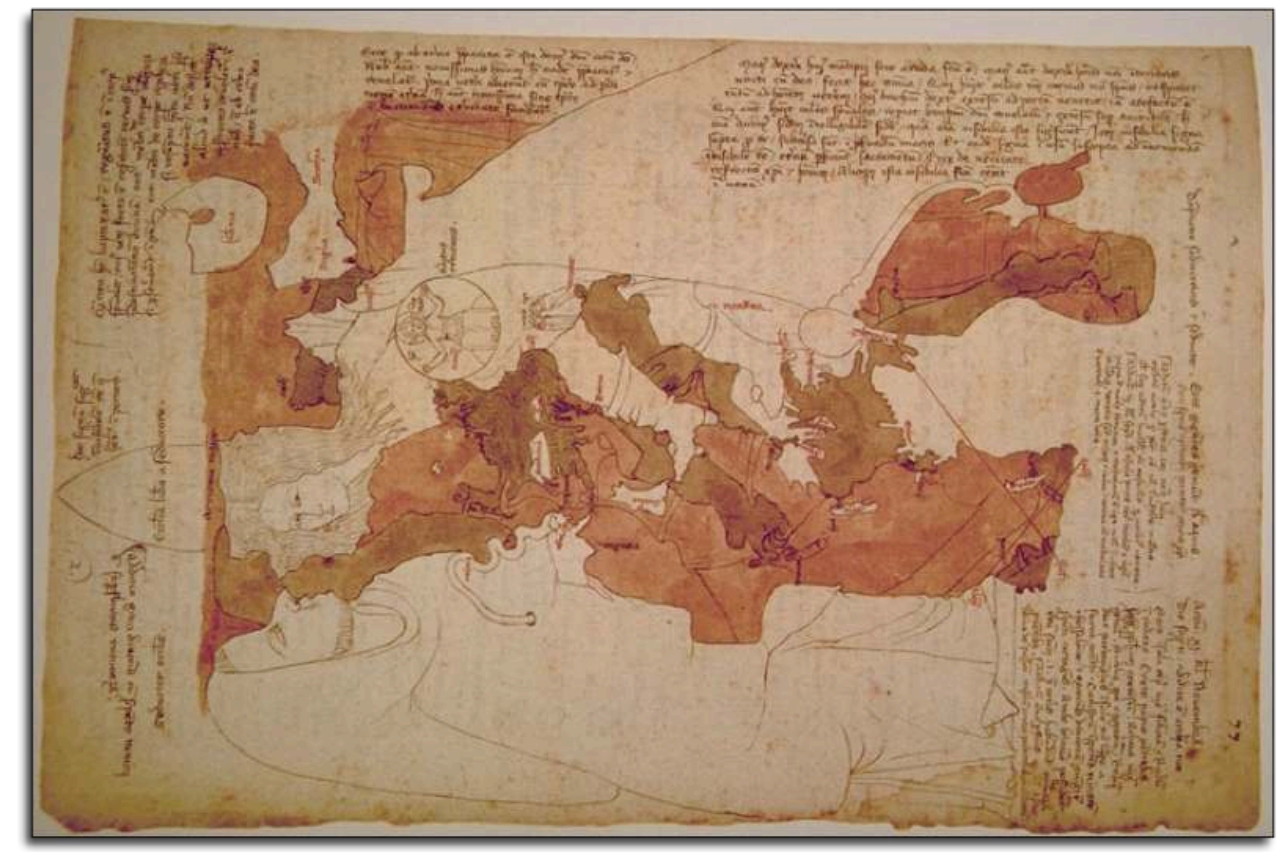

Biblioteca Apostólica Vaticana, Vat. lat. 6435. Disponible en: <https://es.wikipedia.org/wiki/ Archivo:Opicinus_de_Canistris_world_map,_1296_\%E2\%80\%93_1300.png>.

Los mapas alegóricos y satíricos tienen un largo pedigree: ya eran géneros cartográficos consagrados y muy populares en la modernidad temprana. Las caricaturas políticas en forma de mapas antropomórficos y zoomórficos se remontan a los dibujos del monje Opicinus de Canistris, del siglo XIV (Figura 1), quien, inspirado en el mapamundi medieval conocido como el mapa de Ebstorf (un mapamundi realizado en un monasterio benedictino de la Baja Sajonia ca. 1300 y que refleja los conocimientos teológicos y simbólicos acerca del mundo conocido más que la forma real de los continentes y lugares representados), transformó gráficamente los esquemas de cartas náuticas de países y océanos en figuras humanas o "cuerpos del mundo" (Whittington, 2014). Para comenzar a argumentar que estos mapas no eran meras ilustraciones libradas a la imaginación de su autor almacena como si fueran creaciones artísticas individuales sino que eran formas de expresión de formas de comprender el mundo, conviene resaltar que muchos de los textos del mapa de Ebstorf proceden de las Etimologías de San Isidoro -un texto escrito entre ca 630, que consiste en una descomunal compilación en la que se sistematiza y condensa todo el conocimiento de su tiempo basada en el origen de las palabras. Fue uno de los textos más estudiados en 
monasterios durante la Edad Media e incluso no perdió vigencia durante los siguientes quince siglos: fue muy leído durante el Renacimiento (como muestra de ello, alcanza con mencionar que se imprimieron al menos diez ediciones entre 1470 y 1530).

De este ejemplo podemos remarcar dos elementos contextuales y conceptuales que atraviesan estos géneros cartográficos: (a) la eficacia de este tipo de mapas depende de la posibilidad de acceder a un público capaz de interpretarlos; y (b) la capacidad de movilizar mensajes críticos depende de la habilidad de los diseñadores por crear múltples niveles de lectura que los hagan parecer meras ilustraciones o dibujos decorativos que no representen amenaza alguna.

Ilustremos estas dos cuestiones centrales que caracterizan los mapas satíricos sy alegóricos desde tiempos remotos con otros ejemplos notables. El mapa "Europa Regina", que representa a la Europa continental no sólo como mujer sino como reina, diseñado por Johannes Putsch o Bucius; la primera versión de alrededor de 1537 pero se volvió conocido cuando fue incluido en las múltiples ediciones la célebre Cosmographia del cosmógrafo, cartógrafo y hebraísta alemán Sebastian Münster (Figura 2) que circularon ampliamente en Europa en la segunda mitad del siglo XVI. Este dato revela que el mercado del libro fue una condición fundamental para garantizar el funcionamiento social de los mapas satíricos y alegóricos.

Figura 2. Europa Regina, en la edición de Cosmographia de Sebastian Münster, Basilea, 1570

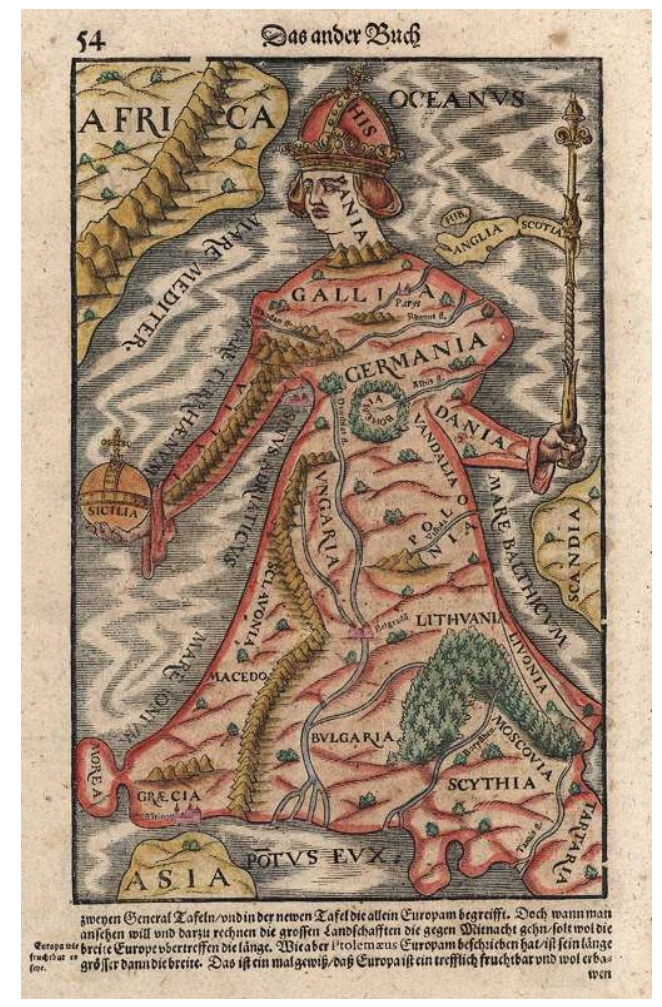

Disponible en: <https://www.wikiwand.com/es/

File:Europe_As_A_Queen_Sebastian_Munster_1570.jpg\#/file>.

11 Otro ejemplo es el llamado Leo Belgicus realizado por Michaël Eytzinger en 1583: el León de Bélgica ${ }^{1}$ (que más tarde ilustró una novela flamenca muy popular) ${ }^{2}$ reclamaba "silenciosamente" y con elegancia la independencia de los Países Bajos de la Corona de España. Sin embargo, la emblemática figura del león belga podía ser vaciada de toda 
suspicacia política y ser leída en clave de figura aglutinadora de identidad o simplemente de un dibujo creativo que podía combinar un símbolo identitario con el lenguaje cartográfico.

La popularidad de este tipo de mapas aumentó notablemente durante el siglo XIX debido a que los desarrollos en las tecnologías de impresión redujeron notablemente el costo de producir fotograbados, revistas y libros, y ello no sólo permitió las tiradas sino que también facilitó y amplió la circulación entre una audiencia más amplia.

13 Al mismo tiempo, la consolidación de la imprenta como potencia social y creador de opinión convertía a los medios de prensa en el Cuarto Poder, "una prensa libre y escéptica que opera más allá del control o la influencia del gobierno, a la vez la medida y la garantía de la libertad política" (Heffernan, 2009: 261). Fueron tiempos de un incremento masivo de la popularidad de las revistas satíricas ilustradas en Europa, especialmente en Francia, Alemania y Gran Bretaña. Entre los casos más célebres, podemos mencionar Le Charivari, publicado por primera vez en 1832 en Francia (Barron, 2008: 458), y luego la muy popular revista estadounidense Puck, originalmente publicada en alemán e inglés, y más tarde sólo en inglés, desde 1871 hasta 1918. Además, durante la segunda mitad del siglo XIX, la expansión de los sistemas educativos y el consecuente aumento de las tasas de alfabetización fueron condiciones que permitieron el aumento del número de lectores potenciales, y así se ampliaron los horizontes intelectuales que facilitaban la interpretación de mapas alegóricos y satíricos.

14 A finales del siglo XVIII, los grabadores y los caricaturistas británicos comenzaron a utilizar cada vez más la cartografía para parodiar los acontecimientos políticos. James Gillray (1756-1815), que fue el autor de la famosa caricatura que muestra cómo el primer ministro británico William Pitt y Napoleón tallaron un "pudín de ciruela" del mundo en rodajas territoriales, produjo Un nuevo mapa de Inglaterra y Francia (1793) que presentaba una Inglaterra antropomórfica que defeca encima de su vecino a través del Canal (Barber 2006). Otro pintor, caricaturista y grabador inglés, Robert Dighton (1752-1814), presentó un conjunto de caricaturas cartográficas de Gran Bretaña (Figura 3) e Irlanda en la fisonomía de viejas brujas, titulando su obra "Geography Bewitched" (publicada en Londres por Bowles y Carver alrededor de 1792). 
Figura 3. Geography Bewitched! (o Caricature Map of England) - Robert Dighton (Londres, 1792)

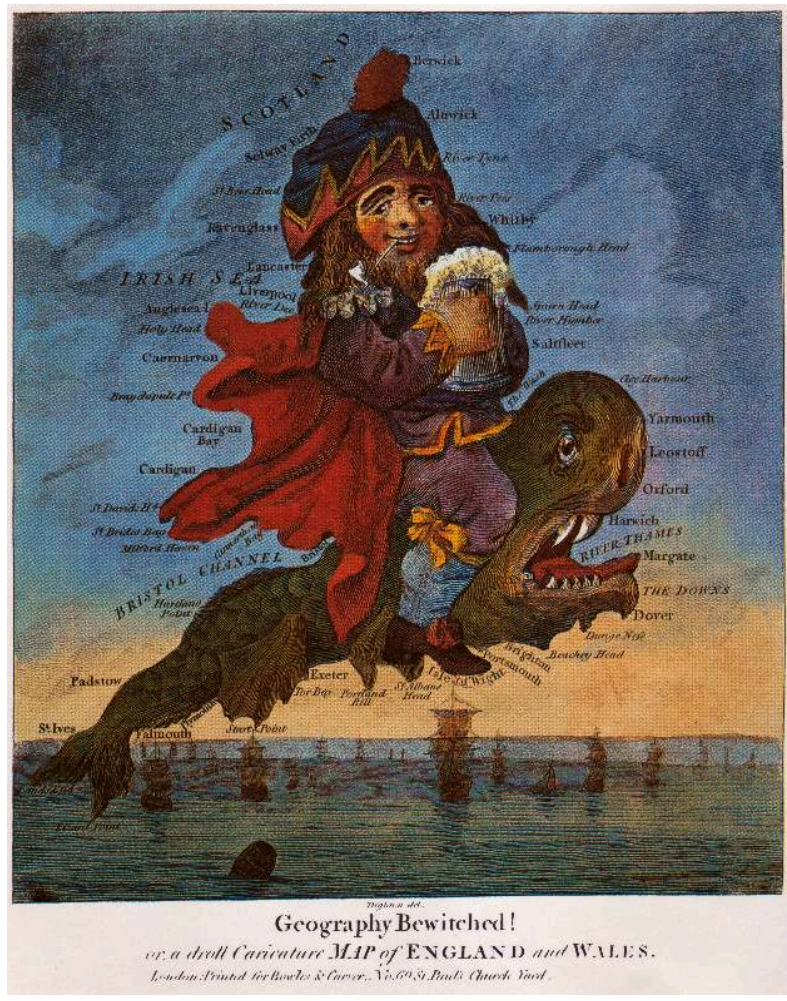

Cortesía Roderick Barron. Disponible en: <https://en.wikipedia.org/wiki/File:Geography_Bewitched__England.jpg>.

Por otro lado, el de Laurie \& Whittle (Londres, 1806) es un "mapa caprichoso" de Europa es uno de los primeros prototipos del mapa de dibujos animados político del siglo XIX, en el que las Islas Británicas son un "viejo y robusto caballero a horcajadas sobre una ballena", una versión híbrida de los tres mapas de caricaturas droll de Inglaterra, Escocia e Irlanda que ya habían sido incluidos en arriba mencionada "Geography Bewitched". La "Descripción poética" debajo del caprichoso Mapa de Europa destaca la posición singular del "viejo robusto" como el gobernante de las olas y el preservador de la libertad, mirando invicto sobre una Europa (compuesta por cada uno de sus países representados simbólicamente) devastada por la tiranía y la guerra napoleónicas (Barron, 2008: 446). Probablemente este sea un ejemplo arquetípico sobre cómo los mapas están insertos y funcionan dentro de una cultura visual al interior de la cual formas de interpretación trasvasan de un dominio a otro y hacen compresibles mapas sin que los lectores tengan algún entrenamiento específico en la codificación imágenes cartográficas.

Los mapas alegóricos fueron también un ornamento didáctico y, a menudo, lúdico. Por ejemplo, "Wanderers in the Wilderness" (Figura 4), un juego geográfico, fue publicado en Londres por Edward Wallis entre 1818 y 1847. Desde el punto de vista de su materialidad, como objeto físico, es una pieza artística: grabado y coloreado a mano, con una cartela profusamente ornamentada en la esquina inferior izquierda donde se aloja el título, "El nuevo juego de vagabundos en el desierto de Wallis", rodeado de pájaros, palmeras, monos, jaguares, un cocodrilo y algunos paisajes estereotipados bucólicos. El juego de mesa tiene dieciséis secciones montadas en lino que muestran un mapa de Sudamérica. Dirigido principalmente al público infantil, tenía la intención de 
enseñar sobre las tierras desconocidas en el extranjero. Siguiendo la dirección del juego (circular, comienzo y final en la costa norte), el juego propone un intrépido recorrido por altas montañas, ríos inmensos, animales grandes y pueblos "primitivos", a lo largo de los 84 casilleros de la carrera. Al mismo tiempo, sus reglas eran bastante similares a las de otros juegos populares, como "Shoots and Ladder" ("Serpientes y Escaleras"). Esto facilitó su rápido éxito financiero, ya que a los niños, familiarizados con este tipo de juegos de mesa, les resultó fácil aprender.

Figura 4. Wallis's New Game of Wanderers in the Wilderness - Edward Wallis, Londres, c. 1844

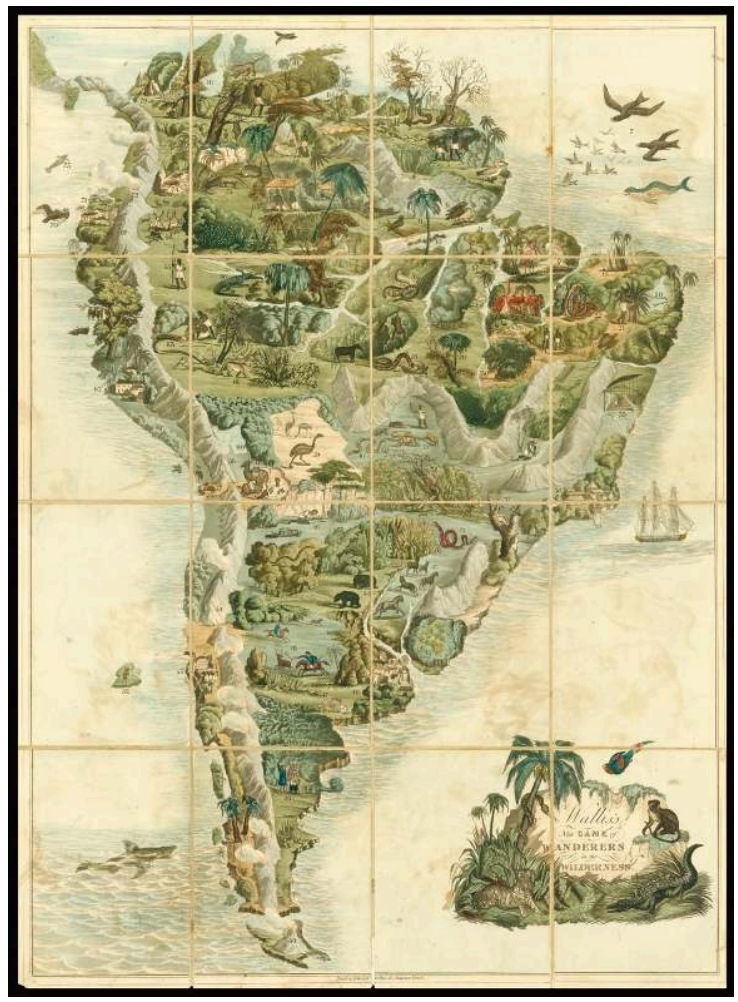

Disponible en: <https://www.crouchrarebooks.com/maps/view/wallis-edward-walliss-new-game-ofwanderers-in-the-wilderness>.

\section{Los mapas alegóricos y satíricos como discursos gráficos y sus funcionamientos sociales}

17 A pesar de la superposición de repertorios iconográficos, estilo humorístico, significados connotativos e intenciones persuasivas entre los mapas alegóricos y satíricos, cada uno de ellos puede definirse como un género cartográfico específico en tanto cada uno enfatiza algunas características específicas. Para hacer esta distinción es útil la definición de género cartográfico: la categoría de géneros cartográficos es una adaptación del uso que se hace de este giro en la crítica literaria y, especialmente, de la concepción bajtiana del término. Esta categoría asume que las construcciones del lenguaje pueden agruparte según tipos relativamente estable en cuanto al contenido temático, al estilo lingüístico (la selección de recursos léxicos, fraseológicos y gramaticales del idioma) y la construcción compositiva (Bajtín, 2011: 11) y, a partir de esa concepción, proponemos pensar que todo género cartográfico comparte un 
contenido temático, un estilo iconográfico, y una arquitectura visual que los emparenta. Considerando estas cuestiones, es posible distinguir dos tipos de mapas que, aunque son muy próximos, mantienen singularidades que permiten definirlos como géneros relacionados pero diferentes.

\subsection{Mapas alegóricos: personificación, animalización y emblemas para significados altamente simbolizados}

18 En los mapas alegóricos, los valores atribuidos a personajes, animales y figuras emblemáticas o mitológicas se resignifican para construir y comunicar ideas sofisticadas sobre países, imperios o incluso el orden moral y político establecido. En general, tienen una intención instructiva, aunque no exenta de propuestas contestarías.

El libro Geographical Fun: Being Humorous Outlines of Various Countries (Londres, 1869), publicado bajo el seudónimo Aleph, está compuesto por doce representaciones antropomórficas de naciones europeas, cada figura figura vestida con ropas típicas. En la "Introducción", el autor explica que pretendía que "estos enigmas geográficos despierten la alegría de los niños, [porque] la diversión del momento puede conducir a la curiosidad provechosa de los estudiantes jóvenes e infundir a la mente un gusto saludable por tierras extranjeras". Aunque en cierto sentido la propuesta es similar a la del juego "Wanderers in the Wilderness", los diseños de Lancaster y los comentarios de Aleph se destacan por su simbolismo nacional y nacionalista que resuena estruendosamente y que, claramente, interpela a los adultos: Inglaterra asume la identidad de la reina Victoria bajo el disfraz de Britannia gobernando las olas (Figura 4); Rusia está representada por las figuras de un gran oso y del zar Alejandro II , uno de espaldas al otro. Italia, por otra parte, asume la forma del popular patriota italiano, Guiseppe Garibaldi, y Prusia está conformada por las figuras de un suplicante Kaiser, Wilhelm I, presentando notas a su Canciller de Hierro, Otto von Bismarck (Barron, 2008: 450). Es esa versatilidad de niveles de lectura lo que define los usos potenciales de los mapas alegóricos. En los últimos años, la conectividad y las redes se constituyeron en categorías epistemológicas de nuestro tiempo. En cartografía, los mapas que hacen prevalecer las relaciones espaciales se apoyan en una concepción de espacio topológico. El principio del espacio topológico es la condición de conexidad: lo que está junto debe permanecer junto y lo que está separado debe permanecer separado, aunque se alteren las escalas, las formas y los tamaños. En el caso de los mapas alegóricos, se busca entrelazar principios éticos, religiosos, morales e incluso filosóficos en clave topológica. Veamos una definición de mapa que remite a un espacio topológico y un mapa de este tipo: "Un mapa es una forma especializada de lenguaje visual y una herramienta para el pensamiento analógico. Tal como Harley ha remarcado, un mapa sirve, entre otras cosas, como una herramienta mnemotécnica, es decir, un banco de memoria para la información relacionada con el espacio" (Tolías, 2007: 639).

Los mapas alegóricos operan en diferentes niveles según el horizonte intelectual de sus usuarios. Su potencia radica, efectivamente, en esa polisemia que amplifica su impacto social y en su propuesta lúdica que los vuelve fácilmente aceptables aun en condiciones políticamente adversas.

21 En los mapas alegóricos, s parte de este imaginario reconocido como ficticio. Pertenece más específicamente a la familia de los mapas alegóricas. La alegoría expresa una 
noción abstracta a través de una figura, a menudo la de un personaje, dotada de atributos simbólicos. Este es el caso, en geografía, alegorías de ríos o continentes.

\subsection{Mapas satíricos: buen humor para la crítica política}

En muchos casos, el humor pone en acción sistemas y códigos lúdicos también para eludir tabúes y evocar temas conflictivos mediante analogías aparentemente ingenuas, es decir, estableciendo conexiones entre dos cosas, temas o áreas hasta entonces sin relación. Así, el humor, a través de estas combinaciones, entra en el ámbito de lo que está prohibido, y deja en evidencia, a través de este juego formal, un fracaso conceptual, donde el tabú aparece con una corrección sorprendente, innegable formalmente. Los mapas satíricos solían trabajar en asociación con códigos humorísticos como una forma de evadir la censura, multas y otros castigos o sanciones.

Vale la pena recordad someramente que los recursos habituales en la sátira son: a) reducir algo para que parezca ridículo, o examinarlo en detalle para resaltar sus fallas; b) exageración o hipérbole: uno toma una situación real y la exagera hasta tal punto que se vuelve ridícula. La caricatura usa esta técnica; c) yuxtaposición que compara cosas disímiles: ayer y hoy, juventud y vejez, etc., por lo que uno adquiere menos importancia; d) parodia o imitación burlona de las técnicas o el estilo de una persona, para que sean ridiculizados. Estas técnicas suelen usarse en literatura y en artes cinematográficas, y también en los mapas.

El género cartográfico de caricatura política se desarrolló en el período comprendido entre 1848 y 1870 en Europa, años acentuados por la revolución europea, la guerra y la agitación política. No es coincidencia que muchos mapas de caricaturas políticas se publicaran exactamente al mismo tiempo que los acontecimientos trascendentales: la Revolución de 1848, la Guerra franco-austríaca de 1859, la Guerra de Crimea (1853-56) y la Guerra franco-prusiana (1870-71). La agitación política, especialmente la revolución y la guerra, proveyó una munición preparada para los satíricos contemporáneos y la inspiración para los dibujantes y artistas con quienes trabajaron (Barron, 2008: 445).

Uno de los mapas satíricos más famosos es el mapa de guerra Serio-Comic para el año 1877, escrito por el dibujante e ilustrador inglés Frederick W. Rose (Figura 5). Los mapas cómicos de la situación política de Europa a mediados del siglo XIX y la vibrante cultura satírica y panfletaria francesa de la Tercera República Francesa y sus efusivas manifestaciones durante la Guerra Franco-Prusiana de 1870-1871 pueden haber servido de inspiración para el proyecto de Rose. El mapa de Rosa ilustra la crítica situación geopolítica en Europa con una simple estrategia gráfica: todas las naciones europeas (representadas como milicianos adaptados a su respectiva silueta territorial) son amenazadas por Rusia, un pulpo gigante y amenazante cuyas armas limitan Polonia, Turquía y otros países de Europa del Este. La frase "Serio-Comic" hace explícito su enfoque satírico al decir que a pesar de su aspecto de caricatura, sus contenidos eran declaraciones serias. En general, sus dibujos son buenos ejemplos de narraciones visuales del siglo XIX o mapas de historias que contenían opiniones e información y que eran visualmente impactantes $\mathrm{y}$, al mismo tiempo, entretenidos. 
Figura 5. Serio-Comic War Map for the year 1877 - Frederick Rose, Londres, 1877

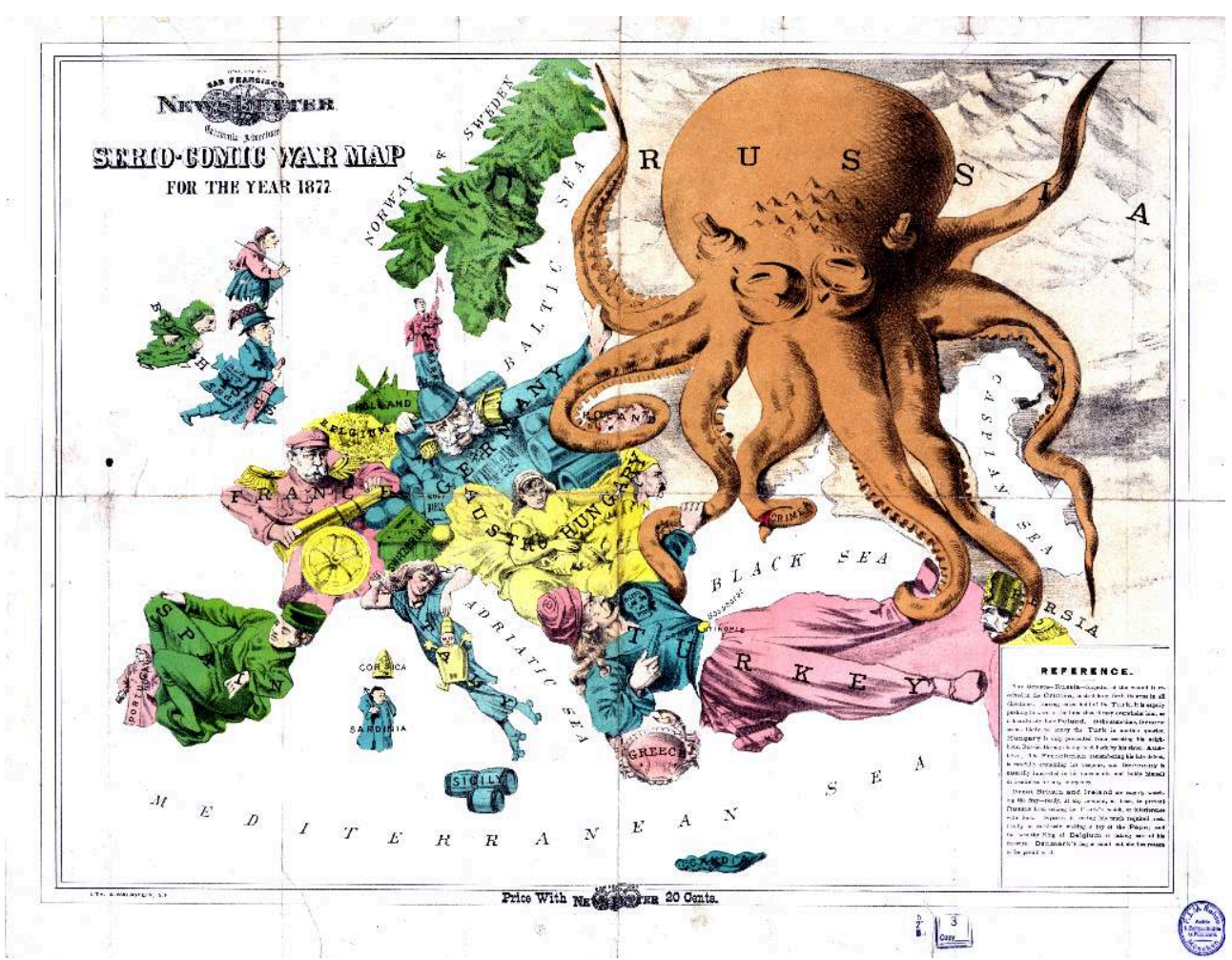

Disponible en: <https://de.wikipedia.org/wiki/Datei:Satirical_map_of_Europe__1877.jpg>.

Este ejemplo nos lleva al reconocimiento de un sistema de código icónico de facto: por ejemplo, el pulpo solía representar al espíritu expansionista como un personaje agresivo y violento (Figura 4). Así puede verse el pulpo del condado de Falmouth que intenta agarrar las parroquias de Falmouth y Budock por Edwin Thomas Oliver (Londres, 1882 entre muchos otros) (Baynton-Williams, 2015: 188-189). El pulpo, como alegoría de la figura expansiva, agresiva y amenazante, se volvió un tópico recurrente y familiar en los mapas satíricos. Fue aplicado a temáticas políticas, económicas y religiosas (entre otras) explotando su connotación negativa para expresar una fuerte crítica a modos de control, poder, sometimiento y jerarquías difíciles de conjurar (Figura 6). 


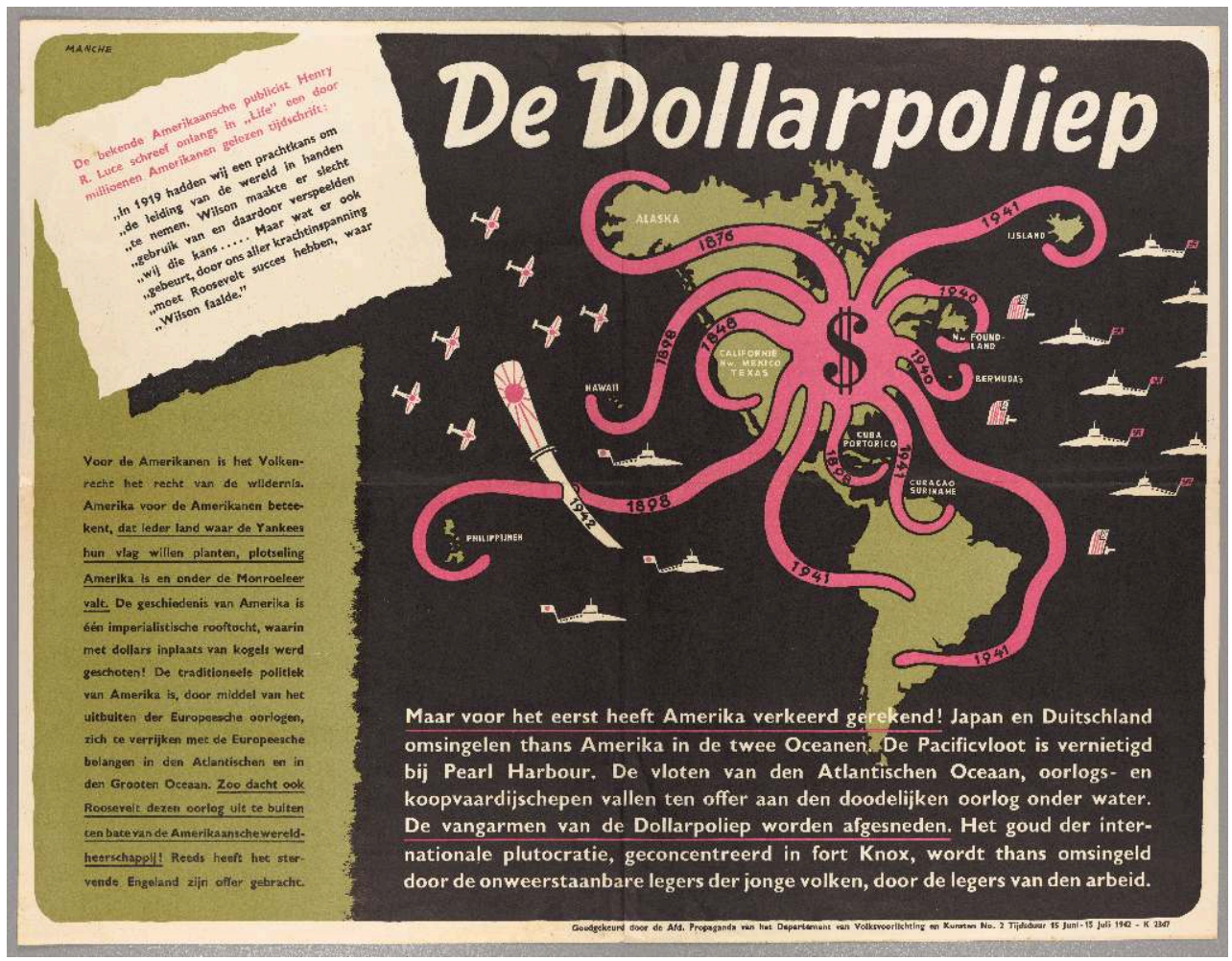

Cortesía Cornell University - PJ Mode Collection of Persuasive Cartography. Disponible en: <https:// digital.library.cornell.edu/catalog/ss:19343543>.

\section{Conclusión}

Los mapas satíricos y alegóricos han sido pensado como metáforas cartográficas que, en rigor, son mucho más que una simple figura retórica utilizada para ornamentar un discurso. La metáfora cartográfica tal como la entendemos aquí son modos de apropiarse de lo cartográfico para crear otras imágenes. Dicho de otro modo: las metáforas cartográficas son imágenes que son reconocidas como mapas (que son llamadas como tales) aunque su función no sea representar geografías sino, más bien, representar otros temas como si fueran geografías. Esto explicaría por qué dejamos fuera de análisis aquí los mapas caricatura, en los que las metáforas (cartográficas, gráficas, lexicales, expresivas e incluso informativas) movilizan diversas figuras retóricas en las que "lo cartográfico" puede ser reemplazado por otras metáforas y es simplemente un recurso eficiente pero no indispensable (Lois, 2015).

Hay que decir que como los mapas alegóricos y satíricos representaban y representan ideas de su tiempo, el simbolismo, las audiencias y los estilos discursivos y gráficos también cambiaron a lo largo el tiempo para garantizar su eficacia en la comunicación en sintonía con las culturas visuales en las que se inscriben.

El uso de mapas para expresar ideas alegóricas, fantásticas y satíricas revela la importancia del modelo espacial en la organización del pensamiento: "el mapa se convirtió en el modus scribendi para los fenómenos que de otro modo no serían fácilmente comprensibles. (...) Los paisajes mentales creados por poetas y filósofos en el siglo diecisiete no podrían necesariamente debe ser clasificado con mapas geográficos, 
ya que no se aplican al mundo físico, pero [sí dan cuenta de] otra realidad no menos genuina que era solo indirectamente visible" (Reitinger, 1999: 111).

En estos mapas puede verse que el espacio parece estar ligado de manera constitutiva a la visión de la existencia desde un punto de vista moral, filosófico o religioso. Estos territorios, islas o provincias, etapas y viajes, corresponden al despliegue de un verdadero "pensamiento tópico" (Palsky, 2017: 289). Todo mapa es una "representación gráfica que facilita el conocimiento espacial de cosas, conceptos, condiciones, procesos o eventos que conciernen al mundo humano"3. Además, el mapa es una imagen que permite conocer y superponer estructuras de conocimiento para visualizar las relaciones espaciales que establecen diversos elementos entre sí. Si esos elementos representados en el mapa no son de naturaleza necesariamente espacial, se dice que el mapa, más que una representación entendida en cualquiera de sus acepciones clásicas, es una metáfora. Se trata de una metáfora que crea un espacio. 0 , dicho en otros términos, la metáfora cartográfica es un método de espacialización del pensamiento, y de visualizar esa espacialización. Cuando el mapa funciona como metáfora, las resonancias de las geografías materiales o empíricas pueden ser sumamente débiles o incluso nulas. Sin embargo, permiten pensar espacialmente. ${ }^{4}$

La forma cartográfica funcionó y funciona eficazmente, por tanto, es una técnica de inscripción fértil, un modelo de inteligibilidad, adecuada para organizar conceptos que describen la realidad. Si el refrán popular nos dice que en toda broma hay algo de verdad, tal vez habría que empezar a reflexionar más seriamente qué nos quieren comunicar esos mapas que se nos presentan como chistes cartográficos pero que, con sus mensajes silenciosos, tal vez nos están gritando algunas verdades incómodas.

\section{BIBLIOGRAFÍA}

Baptista, Gregory (2009). Politics, the Press, and Persuasive Aesthetics: Shaping the Spanish Civil War in American Periodicals. PhD diss., Pennsylvania State University, State College PA.

Bajtin, Mijaíl (1985). Estética de la creación verbal. México: Siglo XXI.

Barber, Peter (2006). The map book. Londres: Weidenfeld \& Nicholson.

Barber, Peter y Tom Harper, 2010, Magnificent Maps: Power, Propaganda and Art. Londres: The British Library.

Baynton-Williams, Ashley (2015). The Curious Map Book. Chicago: The University of Chicago Press.

Boggs, Samuel W. (1947). “Cartohypnosis.”. The Scientific Monthly, v. 64, n. 6, pp. 469-476.

Clinton, Craig (2016). "The Pictorial Maps of Fred A. Routledge". Oregon Historical Quarterly, v. 117, n. 1 (Spring 2016), pp. 36-75.

Cosgrove, Denis (2005) "Maps, Mapping, Modernity: Art and Cartography in the Twentieth Century”. Imago Mundi, v. 57, n. 1, pp. 35-54. 
Heffernan, Michael (2009). "The Cartography of the Fourth Estate: Mapping the New Imperialism in British and French Newspapers, 1875-1925". En: Akerman, James R. (Ed.). The Imperial Map: Cartography and the Mastery of Empire. Chicago and London: University of Chicago Press, pp. 261-299.

Lois, Carla (2015). "El mapa, los mapas. Propuestas metodológicas para abordar la pluralidad y la inestabilidad de la imagen cartográfica". Geograficando, v. 11, n. 1. Disponible en: <http:// www.geograficando.fahce.unlp.edu.ar/article/view/Geov11n01a02>.

Lois, Carla (2015b). "El mapa como metáfora o la espacialización del pensamiento". Terra Brasilis (Nova Série) [En línea], n. 6. 2015. Disponible en: <http:// terrabrasilis.revues.org/1553 ; DOI : 10.4000/terrabrasilis.1553>.

Martin, Denis (1997). Images d'Epinal. Quebec: Musée du Quebec.

Padrón, Ricardo (2007). “Mapping Imaginary Worlds”. In: Akerman, James; Karrow, Robert. Maps: Finding Our Place in the World, pp. 255-287.

Palsky, Gilles (2017). "Amour sacré, amour profane. L'espace des cartes comme allégorie". In: Besse, Jean-Marc; Tiberghien, Gilles (Eds.). Opérations cartographiques. Arles: Actes Sud/ENSP, pp. 278-289.

Peters, Jeffrey N. (2004). Mapping Discord: Allegorical Cartography in Early Modern French Writing. Newark, DE: University of Delaware Press.

Reiteinger, Franz (2008). Kleiner Atlas Amerikanischer Überempfindlichkeiten. Berlin: Ritter Verlag. Barron, Roderick M. (2008). “Bringing the Map to Life: European Satirical Maps 1845-1945. Cartes satiriques de l'Europe 1845-1945 ou comment donner de la vie aux cartes". BelGeo. Revue belge de géographie, n. 3-4, pp. 445-464.

Scafi, Alessandro (2006). Mapping Paradise. A history of Heaven on Earth. London : The British Library.

Speier, Hans (1941). “Magic Geography”. Social Research, v. 8, n. 3, pp. 310-330.

Retinger, Franz (1999). "Mapping relationships: allegory, genre and cartographical image in eighteenth-century France and England". Imago Mundi. The International Journal for the History of Cartography, v. 52, pp. 106-130.

\section{NOTAS}

1. Aunque recién fue adoptado como escudo oficial del Reino de Bélgica, ya hacía tiempo que se ensayaban diversas versiones heráldicas que se caracterizaban por llevar como emblema un león dorado sobre un fondo negro, el llamado León Belga o Leo Belgicus (que son las armas del duque de Brabante, ducado que encabezó la rebelión contra el emperador José II, que llevó a la creación de los Estados Unidos Belgas en 1790).

2. El León de Flandes (en neerlandés; De Leeuw van Vlaanderen o de Slag der Gulden Sporen) es una novela histórica, escrita en holandés por el belga Hendrik Conscience en 1838. El relato se desarrolla durante la Guerra Franco-Flamenca y la batalla de Courtrai de 1302.

3. Harley y Woodward (Eds.) (1987). The History of Cartography (Chicago \& London, v. 1, pp. xvi).

4. Sobre el mapa como metáfora, David Hyerle afirmó que "mapear es una rica síntesis de los procesos de pensamiento, de las estrategias mentales, de las técnicas y del conocimiento que permite a los humanos lanzarse a la investigación de lo desconocido, establecer patrones 
espaciales de la información" (p. 9). Hyerle, David (2003). Visual Tools for Transforming Information Into Knowledge.

\section{RESÚMENES}

Los mapas alegóricos y satíricos son un género cartográfico por derecho propio: se permiten el uso de lenguajes gráficos y licencias poéticas para comunicar más eficazmente mensajes irónicos y críticos. Funcionan como poderosas herramientas para la crítica y la propaganda política, por lo general ridiculizando personajes, lugares o eventos. Para resultar eficaces, buscan establecer complicidad o connivencia con un lector informado capaz de acceder a sus declaraciones implícitas o connotadas dentro de una cultura (política y visual) específica, y están destinados principalmente a influir en las opiniones o creencias de los lectores. Este artículo propone examinar algunos casos emblemáticos de mapas satíricos y alegóricos con tres objetivos: en primer lugar, rastrear la arqueología de este tipo de mapas; en segundo lugar, definir los mapas satíricos y alegóricos como géneros cartográficos con sus propias especificidades; y, en tercer lugar, reflexionar sobre la función sociales de estos dispositivos como recursos expresivos.

Allegorical and satirical maps are a cartographic genre in their own right: complex graphic languages and poetic licenses are used to communicate ironic and critical messages more effectively. They function as powerful tools for criticism and political propaganda, usually ridiculing characters, places or events. To be effective, they seek to establish complicity or connivance with an informed reader capable of accessing their implicit or connoted statements within a specific (political and visual) culture, and are primarily intended to influence the opinions or beliefs of the readers. This article proposes to examine some emblematic cases of satirical and allegorical maps with three objectives: first, to trace the archeology of this type of maps; second, to define satirical and allegorical maps as cartographic genres with their own specificities; and, thirdly, to reflect on the social function of these devices as expressive resources.

Les cartes allégoriques et satiriques constituent un genre cartographique très particulier : l'utilisation de langages graphiques et de licences poétiques permettaient de communiquer plus efficacement des messages ironiques et critiques. Ils fonctionnent comme des outils puissants pour la critique et la propagande politique, généralement en ridiculisant des personnages, des lieux ou des événements. Pour être efficaces, ils cherchent à établir une complicité ou une connivence avec un lecteur averti capable d'accéder à leurs déclarations implicites ou connotées au sein d'une culture spécifique (politique et visuelle) et ainsi influencer les opinions ou les convictions des lecteurs. Cet article propose d'examiner quelques cas emblématiques de cartes satiriques et allégoriques avec trois objectifs : premièrement, tracer l'archéologie de ce type de cartes; deuxièmement, définir les cartes satiriques et allégoriques comme des genres cartographiques ayant leurs propres spécificités ; et, troisièmement, réfléchir sur la fonction sociale de ces dispositifs en tant que ressources expressives.

Os mapas alegóricos e satíricos constituem um gênero cartográfico específico: se permitem a liberdade de usar linguagens gráficas e licenças poéticas para comunicar de modo eficaz mensagens irônicas e críticas. Funcionam como poderosas ferramentas para a crítica e a propaganda política, geralmente ridiculizando personagens, lugares ou eventos. Para serem 
eficazes, buscam estabelecer cumplicidade ou a conivência de um leitor informado capaz de compreender suas declarações implícitas ou conotadas dentro de uma cultura (política e visual) específica, e estão destinados principalmente a influir nas opiniões ou crenças dos leitores. Este artigo propõe examinar alguns casos emblemáticos de mapas satíricos e alegóricos com três objetivos: em primero lugar, rastrear a arqueologia desse tipo de mapas; em segundo lugar, definir os mapas satíricos e alegóricos como gêneros cartográficos com suas próprias especificidades; e, em terceiro lugar, refletir sobre a função social desses dispositivos como recursos expresivos.

\section{ÍNDICE}

Palabras claves: mapas alegóricos, mapas satíricos, género cartográfico, propaganda, comunicación gráfica

Palavras-chave: mapas alegóricos, mapas satíricos, gênero cartográfico, propaganda, comunicação gráfica

Keywords: allegorical maps, satirical maps, cartographic genre, propaganda, graphic communication

Mots-clés: cartes allégoriques, cartes satiriques, genre cartographique, propagande, communication graphique

\section{AUTOR}

CARLA LOIS

CONICET/UBA

Grupo de Historia y Epistemología de las Cartografías e Imágenes Técnicas (GHECIT) 